\title{
LEKSIKON ETNOMEDISIN DALAM PENGOBATAN TRADISIONAL SASAK:
}

\section{KAJIAN ANTROPOLINGUISTIK}

\section{ETHNOMEDICINE LEXICONS OF SASAK TRADITIONAL MEDICATION: AN ANTHROPOLINGUISTIC STUDY}

\author{
Pahrudin Arrozi, Burhanuddin, Saharudin
}

Universitas Mataram

Ponsel: 085933086120; Pos-el: pahrudinarrozi5@gmail.com

\begin{abstract}
Abstrak
Penelitian ini bertempat di Desa Sengkerang dialek Meno-Mene, Kecamatan Praya Timur, Kabupaten Lombok Tengah. Tujuan penelitian ini untuk mendeskripsikan leksikon etnomedisin dalam pengobatan tradisional Sasak. Pendekatan teoretis yang digunakan adalah pendekatan antropolinguistik. Sementara itu, pendekatan metodologis penelitian menggunakan metode deskriptif kualitatif. Untuk pengumpulan data menggunakan studi pustaka, observasi, wawancara dan metode simak dengan teknik dasar berupa teknik sadap dan catat. Hasil penelitian ini pertama, leksikon etnomedisin dalam pengobatan tradisional Sasak di Desa Sengkerang diklasifikasikan menjadi dua bentuk, yaitu kata dan frasa. Kedua, terdapat tiga pandangan budaya leksikon etnomedisin dalam pengobatan tradisional Sasak, yaitu adanya keselarasan masyarakat Sasak di Desa Sengkerang dengan alam, adanya keselarasan nilai keagamaan, dan cerminan ekonomis; ketiga, masyarakat Sasak mewariskan pengetahuanya tentang pengobatan tradisional secara turun-temurun, baik dari mulut ke mulut maupun dalam bentuk tulisan.
\end{abstract}

Kata kunci: leksikon; etnomedisin; antropolinguistik

\begin{abstract}
This research is conducted in Sengkerang village, Meno-Mene dialect, Praya Timur sub-district, Lombok Tengah regency. The purpose of this research is to describe the ethnomedicine lexicons of Sasak traditional treatment. The theoretical approach used in this research is the anthropolinguistic approach. While, the methodological approach used is in the form qualitative-descriptive. The data are collected by applying literature review, observation, interviews and listening methods with basic techniques which categorized into tapping and note taking. There are three results which can be drawn from this research. The first result is the ethnomedicine lexicons of Sasak traditional medication in Sengkerang village is classified into two types: words and phrases. The second result shows that there are three cultural views in the ethnomedicine lexicons of Sasak traditional medication: the harmony of Sasak community in Sengkerang village with nature, the harmony of religious values and economic reflection. The third result
\end{abstract}


shows that Sasak community inherits their knowledge about traditional medication handed down for generations by oral way and writing (lontar).

Keywords: lexicons; ethnomedicine; anthropolinguistic

\section{Pendahuluan}

Kebudayaan adalah identitas suatu bangsa. Kebudayaan dapat membedakan bangsa yang satu dengan bangsa lain. Menurut DuBos (1963:416), kebudayaan merupakan sistem yang rumit dan tidak dapat berubah begitu saja. Berikutnya, menurut Haviland (1999:333), kebudayaan adalah seperangkat aturan yang dimiliki kelompok masyarakat. Jika dilaksanakan oleh anggotanya, akan melahirkan prilaku yang dianggap layak dan dapat diterima oleh seluruh anggota masyarakat tersebut. Selain itu, kebudayaan juga dapat memengaruhi pengetahuan, seperti ide atau gagasan yang terdapat dalam pikiran manusia.

Wujud dari kebudayaan yaitu gagasan, ide, nilai, norma, aturan, dan sebagainya. Hal tersebut ditujukan untuk membantu kelompok atau komunitas masyarakat dalam hidup bermasyarakat.

Masyarakat dan budaya memiliki relasi yang sangat erat. Budaya lahir melalui tingkah laku manusia yang lamakelamaan menjadi tradisi. Sementara itu, budaya yang terdapat di suatu daerah berbeda dengan daerah lain. Hal demikian disebabkan oleh latar belakang berbeda sehingga mempengaruhi cara bersikap dan bertingkah laku masyarakat berbeda-beda. Kebudayaan yang beragam ini menjadi keunikan tersendiri, salah satunya dalam hal pengobatan tradisional.

Pengobatan tradisional adalah salah satu kekayaan tradisi dalam kebudayaan Indonesia. Pengobatan tradisional atau lebih dikenal dengan pengobatan alternatif merupakan cara pengobatan yang memanfaatkan tumbuhtumbuhan dan hewan untuk mengobati berbagai penyakit. Namun, dilihat dari jumlah pemanfaatannya, tumbuhan lebih banyak dimanfaatkan oleh masyarakat.

Menurut Almos dan Pramono, (2015:44-53), pengobatan tradisional hingga hari ini tetap ada, di samping praktik-praktik pengobatan modern semakin berkembang pesat. Sementara itu, dapat kita lihat bahwa masyarakat lebih banyak memilih pengobatan tradisional karena dianggap lebih mudah dijangkau dan ekonomis.

Pengobatan tradisional Sasak dapat diketahui secara lisan dan tulisan. Pengobatan tradisional yang secara lisan (folklor) dapat ditemukan di dalam lingkup masyarakat. Dalam bentuk tulisan, 
dapat ditemukan dalam naskah-naskah kuno (lontar). Untuk mempertahankan pengobatan tradisional Sasak yang dilakukan secara lisan agar tidak hilang, perlu dilakukan pendokumentasian.

Sebagai contoh, masyarakat Sasak yang ada di Desa Sengkerang masih menggunakan alternatif tumbuhan obat untuk menyembuhkan berbagai penyakit. Hal ini disebabkan tumbuh-tumbuhan untuk pengobatan tradisonal mudah didapat, baik yang ditanam atau yang hidup di sawah, kebun, maupun hutan. Mayarakat Sasak di wilayah Desa Sengkerang memiliki kekhasan tersendiri dalam melakukakan pengobatan tradisional. Masyarakat Desa Sengkerang mengklasifikasikan tanaman obat tertentu dalam kelompok jenis tanaman berdasarkan fungsinya. Tanaman-tanaman tersebut dilabeli dengan leksikon tertentu. Dengan kata lain, leksikon dengan berbagai leksem memiliki peranan yang sangat penting. Hal tersebut merupakan wadah untuk mengetahui konsep, ide, yang terdapat di dalam satu budaya (Chaer, 2007:5).

Penelitian ini mengisi rumpang penelitian dengan menjadikan praktik etnomedisin sebagai objeknya. Kajian ini menitikberatkan pada praktik etnomedisin yang berfokus pada praktik lingualnya, yaitu leksikon etnomedisin, kemudian dikaitkan dengan makna kultural bagi masyarakat Sasak. Oleh sebab itu, kajian ini berfokus pada bidang kajian linguistik antropologi.

Kaitan dengan penelitian, ada beberapa penelitian yang mengambil masyarakat Sasak sebagai objek kajian, yaitu Saharudin (2019), Yamin dkk (2008), Diana (2019), Rosana (2018), dan Sarwadi (2019). Penelitian Saharudin (2019) meskipun mengambil objek bahasa Sasak, tetapi membahas dua poin penting dari etnofilsafat padi. Pertama, penelitian ini menjelaskan bagaimana berbagai simbol bahasa dan budaya dan mitos lokal beras dalam masyarakat Sasak dalam masyarakat Sasak. Kedua, penelitian ini membahas simbol dan mitos yang dimodifikasi dalam masyarakat Sasak yang mengandung kesamaan dengan yang ada dalam budaya Melayu seperti yang tercatat dalam naskah Hikayat Asay Pade dan Kitab berladang. Penelitian Yamin dkk (2018) membahas jenis penyakit dari lima naskah lontar Usada, tercatat 324 jenis penyakit. Namun, setelah ditabulasi dan dibandingkan antara terjemahan naskah satu dengan naskah yang lain, diperoleh sebanyak 263 jenis penyakit. Penelitian Juimiati dkk (2019) membahas tentang kata, gabungan kata, istilah, 
ungkapan dan tradisi dalam masyarakat Samawa yang berperspektif gender. Penelitian Rosana (2018) membahas pertama, bentuk ekspresi verbal perkawinan Suku Sasak dan Suku Samawa; kedua, membahas makna simbol dalam perkawinan adat Suku Sasak dan perkawinan adat Suku Samawa. Penelitian Sarwadi (2019) membahas tentang variasivariasi leksikal bahasa Sasak Dialek KutoKute (BSDK) yang dipraktikkan oleh masyarakat Sasak Kabupaten Lombok Utara (KLU). Dengan demikian, penelitian-penelitian tersebut dilihat dari aspek dan objek kajiannya secara antropolinguistik berbeda dengan penelitian ini.

\section{Landasan Teori}

Leksikon yaitu kata, ucapan, atau cara bicara (Chaer, 2007:2). Kata leksikon memiliki kesamaan dengan leksikografi, leksikograf, leksem, leksikal, dan sebagainya. Kumpulan leksem dalam satu bahasa disebut leksikon. Di dalam leksikon terdapat kata, kosakata, pembelajaran kata, penggunaan kata, sejarah dan perubahan kata, hubungan antarkata, serta proses pembentukan kata.

Etnomedisin merupakan salah satu ranah kajian bidang tumbuhan (etnobotani). Etnomedisin berusaha untuk mengungkap pengetahuan masyarakat tentang tata cara menjaga kesehatan. Pengobatan tradisional, khususnya pengobatan tradisional masyarakat Sasak memanfaatkan tumbuhan dan hewan untuk mengobati penyakit. Akan tetapi, dilihat dari jumlah pemanfaatannya tumbuhan lebih banyak digunakan. Hal ini membuat pengobatan tradisional identik sebagai tumbuhan obat. Menurut Jumiani dan Komalasari (2017:45--56), tumbuhan obat tradisional adalah bahan ramuan alami yang telah digunakan untuk mengobati penyakit berdasarakan pengalaman kelompok masyarakat. Dengan adanya keanekaragaman tumbuhan obat di lingkungan, kelompok masyarakat dapat memenuhi ketersedian bahan obat-obatan tradisional. Hal tersebut terkait dengan cara pemerolehan bahan pengobatan, yaitu pengaruh lingkungan, pengaruh manusia, pengaruh bangunan, pengaruh ide generasi muda, dan revitalisasi (Sibarani, 2016:169--17).

Etnomedisin berasal dari dua kata, yaitu kata ethno yang berarti etnis dan medicine yang berarti obat. Dalam hal ini, etnomedisin memiliki relasi yang sangat erat antara etnis dan obat. Sementara itu, secara ilmiah etnomedisin adalah presepsi dan konsepsi yang dipahami oleh sekelompok masyarakat (etnis) terkait hal 
kesehatan atau studi tentang medis etnis tradisional (Daval, 2009). Selain itu, menurut Walujo (2009), studi etnomedisin dapat dilihat dari sudut pandang masyarakat (emic) yang dipahami sebagai budaya kesehatan dan kemudian dibuktikan dengan cara ilmiah (etic).

Konsep dasar etnomedisin merupakan bagian dari antropologi kesehatan yang mengkaji dan mengupas asal mula penyakit, penyabab penyakit, dan cara penanganannya atau pengobatan menurut suatu kelompok masyarakat. Aspek etnomedisin mulai tampak seiring perkembangan kebudayaan di masyarakat tertentu. Dalam kajian antropologi kesehatan, sebuah termonologi yang dimunculkan etnomedisin sering disebut dengan pengobatan tradisional (primitif). Namun, istilah etnomedisin lebih tepat digunakan (Foster dan Anderson, 1986:62).

Antropolinguistik adalah bagian ilmu yang memiliki sifat interpretatif. Hal ini bermaksud mengupas dan membahas bahasa lebih dalam untuk mendapatkan pemahaman budaya. Menurut Duranti (2002), antropologilinguistik yaitu sumber budaya yang mengkaji bahasa dan praktik budaya tuturannya. Artinya, budaya dan pengetahuan bersama masyarakat berfungsi untuk menjelaskan makna tuturan sebagai praktik dari budaya itu.

Bahasa dan budaya cenderung memiliki arti luas (Palmer, 1996). Ia mengatakan bahwa antropolinguistik berkembang melalui tiga tradisi, yaitu (1) melalui tradisi boas; (2) melalui etnosemantik; dan (3) melalui etnografi. Pendekatan melalui tradsi boas lebih menekankan penjelasan-penjelasan tata bahasa. Melalui tradisi etnosemantik, lebih menekankan tentang cara-cara mengelompokkan ilmu pengetahuan berdasarkan budaya yang berbeda-beda. Sementara itu, tradisi melalui etnografi merupakan pelukisan penutur yang memiliki tujuan tertentu dalam memakai bahasanya dan disesuaikan dengan konteks sosialnya (Palmer, 1996: 10--19).

Menurut Beratha (1998:45), antropolinguistik difokuskan pada makna alamiah meta-bahasa yang terdiri atas beberapa kajian, yaitu mulai dari kajian budaya, kajian wacana kebudayaan, kajian komunikasi lintas budaya, kajian etnografi berbahasa, serta kajian kebudayaan dan perubahan bahasa.

\section{Metode Penelitian}

Secara metodologis, pendekatan yang digunakan dalam penelitian ini adalah pendekatan deskriptif kualitatif. 
Pendekatan ini berupa data lisan dari ujaran setiap orang dan mengamati perilakunya. Metode kualitatif digunakan untuk menjabarkan bentuk-bentuk lingual yang ada pada leksikon bahan pengobatan tradisional dan nama-nama penyakit tradisional. Tahapan yang digunakan dalam penelitian ini yaitu pertama, penyediaan data; kedua, analisis data; dan ketiga, penyajian data. Dalam penelitian ini, digunakan metode simak dengan teknik dasar berupa teknik sadap dan catat untuk penyediaan data awal (Sudaryanto, 1990:131--143).

Selanjutnya, data penelitian yang dijelaskan dalam tulisan ini adalah leksikon pengobatan tradisional Sasak (etnomedisin). Kemudian, dilanjutkan dengan mencari leksikon nama-nama penyakit di dalam bahasa Sasak. Teknik analisis dilakukan melalui beberapa tahapan, antara lain: (1) mengidentifikasi data analisis; (2) mendeskripsikan dan mengklasifikasikan data berdasarkan bentuk lingual; (3) mendeskripsikan data berdasarkan fungsi leksikon; dan (4) menyimpulkan.

Dalam pengumpulan data, digunakan studi pustaka, observasi, serta wawancara. Selain itu, peneliti juga mengamati setiap tata cara pengobatan tradisional Sasak (etnomedisin), khususnya yang mengandung unsur lingual pada masyarakat Sasak, Desa Sengkerang, Kecamatan Praya Timur. Pengamatan ini dilakukan peneliti dengan cara penyadapan dengan teknik turunan, yaitu simak bebas libat cakap, rekam, dan catat (Sudaryanto, 1993).

Metode simak digunakan untuk mendengar penggunaan bahasa. Maksudnya, penyimakan dilakukan berkaitan dengan penggunaan bahasa secara lisan dan tertulis (Mahsun, 2017). Metode dan teknik yang digunakan tersebut dilakukan secara kontinu, sistematis, serta komprehensif.

Teknik wawancara dilakukan untuk mendapatkan data sekunder, yaitu tuturan masyarakat. Sumber data dalam penelitian ini adalah sumber data primer dan sumber data sekunder. Data yang didapatkan di lapangan atau diambil dari informan (masyarakat Sasak) sebagai sumber data primer. Sumber data primer ditempuh melalui participant observation. sedangkan, untuk data sekunder menggunakan sumber kepustakaan.

Beberapa orang yang memiliki pengetahuan dan keahlian dalam pengobatan tradisional (etnomedisin) dengan menggunakan tumbuhan obat dalam ramuannya dijadikan informan penelitian ini. Untuk pengumpulan data 
dilakukan dengan cara bertatap muka atau wawancara.

\section{Pembahasan}

Berdasarkan hasil penelitian, penelitian ini mendeskripsikan dan mengklasifikasikan leksikon etnomedisin dalam pengobatan tradisional Sasak, khususnya di Desa Sengkerang, Kecamatan Praya Timur berdasarkan bentuk-bentuk lingual dan makna budaya yang terkandung di dalamnya, serta mendeskripsikan cerminan budaya yang ada pada leksikon-leksikon tersebut.

\subsection{Klasifikasi Leksikon Pengobatan Tradisional Sasak}

Secara umum, ditemukan 71 leksikon nama tanaman obat-obatan berdasarkan bahan yang digunakan dalam pengobatan tradisional Sasak. Nama-nama tumbuhan obat tersebut yaitu (1) Daun bikan, (2) Pusuk bikan, (3) Daun periq, (4) Pusuk tereng, (5) Daun bakong, (6) Adas, (7) inen kunyiq, (8) Sekuh, (9) Saq-saq, (10) Beras lase, (11) Likoq, (12) Buaq, (13) Lulun namplok, (14) Upeq, (15) Sang putiq, (16) Inen kunyiq, (17) Akah lemerong, (18) Babak banten, (19) Babak joet, (20) Beras lase, (21) Pusuk banten, (22) Daun bikan, (23) Ate bawang, (24) Daun sebie, (25) Daun terong aceh, (26) Daun sekuh, (27)Pusuk puntiq (yang baru keluar dari tanah), (28) Daun loam, (29)
Jagung gero, (30) Daun nangke, (31) Pusuk kayu dui, (32) Sang, (33) Daun pki (dikunyah), (34) Getah jarak, (35) Pohon pisang, (36) Buaq nyambuq batu, (37) Daun ketujur, (38) Daun kelor, (39) Babak randu, (40) Babak kuste, (41) Babak asem, (42) Sebie tandan, (43) Jae, (44) Daun lemuwuq, (45) Pusuk loam, (46) Daun banten, (47) Daun ketangge, (48) Pusuk nyambuq, (49) Daun berung, (50) Daun kepeti (putri malu), (51) Empet-empet, (52) Daun renggas, (53) Daun belate tame, (54) Kembang lembain, (55) Daun legu, (56) Kembang gedang ranti (tidak berbuah), (57) Daun jeruk, (58) Ketumbar, (59) Pusuk daun aur, (60) Akah re, (61) Akah tereng (yang ujungnya patah), (62) Marica, (63) Mute kelep, (64) Akah user, (65) Ambon jamak, (66) Daun Alpokat (67) Jerengo, (68) Lensune, (69) Daun ambon jawe, (70) Kangkung, dan (71) Alpokat.

Seluruh data yang didapat kemudian dilakukan pengklasifikasian berdasarkan bentuk lingualnya, yaitu bentuk kata dan bentuk frasa. Leksikon yang masuk ke dalam bentuk kata diklasifikasikan lagi menjadi bentuk tunggal dan bentuk ulang. Dari keseluruhan data yang ada, terdapat 15 leksikon yang berbentuk kata dan 56 leksikon yeng berbentuk frasa. Leksikon 
dalam bentuk tunggal, yaitu adas, sekuh, likoq, buaq, upeq, sang, jae, ketumbar, marica, jerengo, lensune, kangkung, alpokat. Leksikon bentuk ulang, yaitu saqsaq dan empet-empet.

\subsection{Klasifikasi Leksikon Nama Penyakit Tradisional Sasak}

Secara keseluruhan, berdasarkan analisis deskriptif yang telah dilakukan, ditemukan adanya 29 leksikon berdasarkan nama penyakit tradisional Sasak yang didapat. Nama penyakit tersebut, yaitu (1) Tiwang, (2) Panas (anak kecil), (3) Budun (bisul), (4) Letak nai, (5) Koreng, (6) Pineng (anak kecil), (7) Leket, (8) Sakit tian (mules), (9) Sakit seruq, (10) Sakit kentok, (11) Besalaq (kaki atau tangan), (12) Endaraq aiq susu, (13) Sakit keng, (14) Ngayah (penyakit pada kulit), (15) Pineng (untuk orang dewasa), (16) Baq tian, (17) Telih panas, (18) Panas dalem (anak kecil), (19) ndaraq balung (lemas), (20) Denggong, (21) Bakeq beraq, (22) Ransek, (23) Kurang daraq (kurang tidur/tidak bisa tidur), (24) amar Jaran (melak mangan maraq jaran/ makan rakus), (25) amar godek (anak kecil suka menggagaruk), (26) amar rupeq (kulit anak kecil yang tipis), (27) amar santen (kuning bungah/ suka mengantuk), (28) amar gerenggeng (kurus kering), dan (29) amar lampin (lemas seperti lampin).
Berdasarkan bentuk kata, dari 29

leksikon nama-nama penyakit tradisional Sasak, terdapat 9 leksikon yang merupakan bentuk tunggal dan 20 leksikon berbentuk frasa. Leksikon yang bentuk tunggal adalah tiwang, pineng, koreng, leket, panas, ngayah, pineng, denggong, dan ransek.

\subsection{Cerminan Budaya Etnomedisin dalam Pengobatan Tradisional Sasak}

Studi tentang etnomedisin pada dasarnya berkenaan dengan upaya mengetahui budaya kesehatan suatu kelompok masyarakat, terutama dari sistem pengobatan tradisional yang telah diwariskan dan menjadi tradisi. Dari sudut pandang etnomedisin, penyakit atau sakit dapat disebabkan oleh personalistik dan natural atau nonsupranatural. Sakit yang disebabkan personalistik yaitu sakit karena agen (tokoh), misalnya dewa, makhluk halus, manusia, dan seterusnya. Sakit natural atau nonsupranatural yaitu sakit yang disebabkan karena daya tahan tubuh yang lemah, misalnya sakit panas dan dingin.

Dalam konteks linguistik antropologi, bahasa dapat dijadikan sebagai instrumen untuk menemukan pemahaman budaya (cultural understanding) karena bahasa dapat dipandang sebagai sumber daya kultural 
dan praktik lingualnya dianggap sebagai praktik kultural. Artinya, cerminan budaya suatu masyarakat dapat tersimpan dari praktik bahasanya. Kemudian, budaya sebagai pengetahuan bersama kelompok masyarakat dapat berfungsi sebagai instrumen dalam menjelaskan makna tuturan dari praktik budaya tersebut.

Praktik lingual yang ada pada suatu masyarakat akan menampilkan realitas kultural yang mereka miliki. Atas dasar itulah, setiap realitas lingual akan menyimpan cerminan kultural dari mental penuturnya. Setidaknya, ada tiga cerminan budaya yang ada dalam leksikon etnomedisin pengobatan tradisional Sasak, yaitu (a) keselarasan masyarakat Sasak dengan alam, (b) adanya keselarasan nilai keagamaan, dan (c) cerminan ekonomis.

Cerminan harmonisasi masyarakat dengan alam maksudnya adalah masyarakat Sasak sangat menjaga optimalisasi kekayaan alam di sekitar mereka dengan memanfaatkannya sebagai bahan pengobatan tradisional. Padahal, realitas kultural telah memperlihatkan adanya perubahan yang masif menuju era modern dengan berbagai kompleksitasnya yang ada pada hampir seluruh aspek kehidupan masyarakat. Meskipun demikian, masyarakat Sasak masih tetap menjaga kekayaan budayanya karena diwariskan dari generasi sebelumnya mengenai pengetahuan tentang sistem pengobatan tradisional. Kondisi ini terus berlangsung sampai masa sekarang. Cerminan ini diperlihatkan oleh leksikon etnomedisin, khususnya berkenaan dengan bahan pengobatan tradisional yang berasal dari bagian tumbuhan dan tanaman obat. Optimalisasi tanaman dan tumbuhan obat tersebut mendorong masyarakat Sasak menjaga interaksinya dengan alam sekitar serta akan lebih peduli terhadap pelestarian kekayaan alam dengan segala kompleksitasnya tersebut. Cerminan kultural itu dapat dipahami sebagai sebuah kondisi yang menampilkan adanya kerja sama simbiosis mutualisme yang terjalin antara manusia dengan alam dalam praktik pengobatan tradisionalnya. Dari relasi ini, terlihat jelas bahwa manusia memerlukan alam sebagai sumber bahan pengobatan tradisionalnya dengan tanpa upaya merusak dan membiarkan alam sekitarnya mengalami kerusakan. Simbiosisi mutualisme yang terjalin menghendaki adanya upaya yang serius dari masyarakat untuk menjaga dan melestarikan kekayaan alam tersebut.

Harmonisasi nilai religius terhadap alam maksudnya adalah berkenaan dengan keberadaan alam termasuk di dalamnya tumbuhan dan tanaman obat merupakan 
hasil penciptaan Tuhan. Seperti cerminan kultural pertama, cerminan kultural kedua juga berkenaan dengan bahan pengobatan tradisional Sasak yang merupakan leksikon-leksikon yang berasal dari penamaan dan jenis yang berasal dari alam, seperti daun bikan, pusuk bikan, daun periq, pusuk tereng, daun bakong, adas, inen kunyiq, sekuh, saq-saq, beras lase, likoq, buaq, lulun namplok, upeq, sang putiq, inen kunyiq, akah lemerong, babak banten, babak joet, beras lase, pusuk banten, daun bikan, ate bawang, daun sebie, daun terong aceh, daun sekuh, pusuk puntiq, daun loam, dll. Penamaan leksikon bahan pengobatan tradisional Sasak yang diambil dari tumbuhan dan tanaman obat yang ada di sekitar mereka menjadi bukti adanya penghargaan masyarakat terhadap nikmat yang Tuhan anugerahkan berupa kekayaan alam yang dapat dimanfaatkan sebagai bahan pengobatan bagi mereka. Timbal balik dari relasi ini dapat berupa adanya pemanfaatan, penjagaan, pelestarian, dan optimalisasi tanaman-tanaman tersebut dengan bijak. Hal ini menjadi bukti adanya rasa syukur manusia kepada Tuhannya. Dari cerminan ini, dapat dipahami bahwa masyarakat Sasak, khususnya di Desa Sengkerang merupakan masyarakat yang religius.
Cerminan ekonomis maksudnya adalah bahwa dalam praktik etnomedisin dengan memanfaatkan kekayaan alam berupa tumbuhan dan tanaman obat terdapat upaya pemenuhan dan penghematan kebutuhan sehari-hari (bersifat ekonomis).

\subsection{Gejala Budaya Etnomedisin dalam Pengobatan Tradisional Sasak}

Dalam kaitannya dengan sistem pengetahuan pengobatan tradisional masyarakat Sasak, pengetahuan tentang tuтри atau bahan pengobatan tradisional diwariskan secara turun menurun. Proses pelestarian tersebut telah berjalan sangat lama, bahkan setiap orang sejak kecil telah diajarkan oleh orang tuanya dalam pemanfaatan tanaman-tanaman tertentu yang dijadikan sebagai obat alternatif. Tanaman-tanaman tersebut mudah untuk didapatkan, bahkan tersebar di lingkungan sekitar tempat tinggalnya, seperti di hutan, ladang, pekarangan, dan halaman. Jenisjenis tumbuhan yang dijadikan bahan pengobatan banyak digunakan dalam pengobatan berbagai jenis penyakit, khususnya masyarakat Sasak, seperti penyakit tiwang, budun, pineng, leket nai, sakit seroq, sakit tian, dan sebagainya.

Tanaman dan tumbuhan yang dimanfaatkan untuk dijadikan obat tradisional tersebut mudah diperoleh, bisa didapatkan di antara persawahan, ladang, 
atau hutan. Masyarakat masih jarang yang dengan sengaja menanamnya di pekarangan rumah. Apabila mereka memerlukan tanaman itu untuk diramu dijadikan obat, biasanya mereka akan mencari di semak-semak belukar dan sawah. Hal itu akan menjadi masalah apabila tanaman tersebut diperlukan mendadak dan pasien membutuhkan penanganan dengan segera.

Oleh karena itu, masyarakat Sasak akhirnya menyadari akan pentingnya menanam berbagai jenis tumbuhan dan tanaman obat di sekitar rumah, misalnya menamam kunyiq, likoq, buaq, dll. Langkah tersebut dapat menjadi langkah pertama untuk membuat kebun apotek. Konsep kebun ini sepertinya sudah mulai diberlakukan di beberapa daerah, khususnya oleh masyarakat yang menyadari pentingnya menanam tumbuhan obat, terlebih seiring adanya upaya global untuk menjaga dan melindungi lingkungan, "kembali ke alam" atau back to nature. Kebun apotek hidup dapat dipahami sebagai sebuah lahan kosong yang ada di sekitar pekarangan rumah, di dalamnya ditanami berbagai macam tumbuhan dan tanaman yang mengandung khasiat obat untuk dijadikan ramuan berbagai macam penyakit.
Keuntungan adanya kebun apotek hidup ini adalah akan memudahkan masyarakat untuk mengakses dan mendapatkan berbagai macam tumbuhan dan tanaman obat tradisional jika sewaktuwaktu diperlukan mendadak. Manfaat lainnya dari kebun apotek hidup ini adalah adanya upaya preservasi atau regenerasi serta pelestarian pengetahuan kultural mengenai kearifan lokal mengenai pengobatan tradisional berbasis tanaman. Dengan seperti itu, pengetahuan generasi muda tentang berbagai tanaman dan tumbuhan yang berkhasiat obat akan semakin mudah dijaga dan dilestarikan.

\section{Penutup}

Seluruh data yang diperoleh dilakukan pengklasifikasian berdasarkan bentuk lingualnya menjadi bentuk kata dan frasa. Leksikon yang masuk ke dalam bentuk kata diklasifikasikan menjadi bentuk tunggal dan bentuk ulang. Dari keseluruhan data yang ada, terdapat 15 leksikon yang berbentuk kata dan 56 leksikon yeng berbentuk frasa. Berdasarkan bentuk kata, dari 29 leksikon nama-nama penyakit tradisional Sasak terdapat 9 leksikon yang merupakan bentuk tunggal dan 20 leksikon bebrbentuk frasa. 
Leksikon etnomedisin dalam Diana, Jumianti. (2018). Gender dalam pengobatan tradisional Sasak memiliki tiga cerminan kultural, keselarasan masyarakat Sasak dengan alam, adanya keselarasan nilai keagamaan, dan cerminan ekonomis.

Dalam kaitannya dengan sistem pengetahuan pengobatan tradisional Sasak, terdapat pengetahuan terkait bahan-bahan pengobatan tradisional yang diwariskan kepada generasi muda. Selanjutnya, proses pelestariannya telah berjalan sangat lama, bahkan setiap orang sejak kecil telah diajarkan tentang pemanfaatan tanamantanaman tertentu untuk dijadikan sebagai obat alternatif.

\section{Daftar Pustaka}

Almos, Pramono. (2015). Leksikon Etnomedisin dalam Pengobatan Tradisional Minangkabau. Jurnal Arbitrer. Volume 2: 44--53.

Beratha. (1998). Materi Linguistik Kebudayaan Edisi 9. Denpasar: Program Magister (S2) Linguistik, Universitas Udayana: 45.

Chaer, Abdul. (2007). Leksikologi dan Leksikografi Indonesia. Jakarta: Rineka Cipta.

Daval. (2009). Consevation and Cultivation of Ethnomedicinal Plants in Jharkhand. in: Trivedi, P.C. Medicinal Plants Utilisation and Conservation. Aavishkar Publishers Distributor, Jaipur. India: 130--136.

Mahsun. 2017. Metode Penelitian Bahasa Edisi Ketiga. Depok: PT Raja Grafindo Persada.

Palmer. (1996). Toward A Theory of Culture Linguistics. Austin: University Of Texas Press.

Saharudin. (2019). The Symbols and Myths of Rice in Sasak's Culture A Portrait of Hybrid Islam in Lombok. AlJami'ah: Journal of Islamic Studies. Vol 57 (2): 425--458.

Sarwadi, Gita. (2019). Variasi Leksikal Bahasa Sasak Dialek Kuto-Kute di Kabupaten Lombok Utara. Jurnal Kata: Penelitian tentang Ilmu Bahasa dan sastra. Vol 3 (1): 155. 
Sibarani. (2016). Kosakata Tanaman Tradisional Obat-Obatan dalam Bahasa Batak Toba: Kajian Antropolinguistik. Medan Makna. Vol 14:169--179.

Sudaryanto. (1990). Metode Linguistik ke Arah Memahami Metode Linguistik. Yogyakarta: Gadjah Mada University Press.

Sudaryanto. (1993). Metode dan Aneka Teknik Analisis Bahasa, Pengantar Penelitian Wahana Kebudayaan Secara Linguistik. Yogyakarta: Duta Wacana University Press.
Walujo. (2009). Etnobotani: Memfasilitasi Penghayatan, Pemutakhiran Pengetahuan dan Kearifan Lokal dengan Menggunakan PrinsipPrinsip Dasar Ilmu Pengetahuan. Prosiding Seminar Etnobotani IV, Cibinong Science Center-LIPI: 12-20.

Yamin. Burhanudin. Jamaluddin. \& Nasruddin. (2018). Pengobatan dan Obat Tradisional Suku Sasak di Lombok. Jurnal Biologi Tropis. Vol 18(1): 1--12. 